\title{
PHARMACO-ECONOMIC ASPECTS AND PATTERN OF ANTIBIOTIC PRECRIPTIONS IN FOUR MAJOR HOSPITALS IN KATHMANDU
}

\section{ABSTRACT}

Background: Antibiotics are extensively prescribed drugs and their use is associated with increasing rate of antibiotic resistance. Nearly one third of prescriptions of physicians for colds, upper respiratory tract infections and bronchitis are of anticiotics as documented in previous studies. Antibiotic use is associated with higher cost of prescriptions, which is impracticable to low socioeconomic groups in Nepal. Besides this patients have little knowledge about the use of antibiotics as shown by previous study of antibiotics used in randomly selected 20 private clinics of Kathmandu valley. ${ }^{13}$

To study the prescribing pattern of Antibiotic preparations in various diseases and to find out how the treatment could become more pharmaco-economic in government hospitals, without compromising the quality of service.

The results were as under Total No. of prescriptions audited were 522, average numbers of drugs/per prescription were 2.61 .

Maximum antibiotics were received in age group 21-41 y in gynecological, surgical and medical problems, in Pediatrics maximum antibiotics were prescribed between 1-12 years.

Minimum antibiotics were prescribed between 13-20 y for gynecological and Pediatric problems. In medical and surgical problems, minimum antibiotics was administered between 41-60 years. Above 60 years almost no antibiotics were used.

Males were prescribed more antibiotics then females (73\% for surgical, $62 \%$ for medical and $53 \%$ for Pediatric problems)

Only in $24.5 \%$ patients, antibiotics were prescribed after proper diagnosis and sensitivity tests Maximum cost of Prescription was 638 Nepali Rupees for treatment of sexually transmitted infection in Gynecology.

Key Words: Antibiotics, Cost, Private Clinics, Pharmacoeconomic, Sexually Transmitted Diseases.

\section{INTRODUCTION}

Infectious diseases remain the world's leading cause of death besides cardiac diseases, cancer and automobile accidents. In tropical \& developing countries the pattern of infectious diseases are different where malaria, dengue hemorrhagic fevers are more common, but world wide common infectious diseases are hepatitis, STD, HIV/AIDS.

According to WHO the impact of infectious diseases on human health has been tremendous and fatal. Antibiotic (ANTIBIOTICS) discovery and development of vaccines led

* Nepal Medical College, Kathmandu.

** K.U.M.S., Dhulikhel, Karve.

*** Kathmandu Medical College, Kathmandu.

${ }^{\star * \star *}$ K.U., Karve.

Address for correspondence : $\quad$ Dr. A. C. Jauhari

Nepal Medical College, Jorpati, Kathmandu, Nepal.

Email: acjohorey_7@hotmail.com 
to belief that this impact of diseases could be reduced to some extent. But it was no so, due to development of resistance of micro organisms against antibiotics. ${ }^{1}$ As more and more strong antibiotics are launched in the market everyday leading to more resistant strains of micro-organisms. Finally we are digging deep into the barrel of antibiotics. ${ }^{2}$ Antibiotics are often most

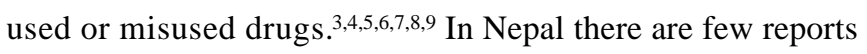
about antibiotic survey. ${ }^{10,11}$

It has been seen that approximately 12 million antibiotics prescriptions resulted from respiratory infections accounting for $21 \%$ of all antibiotics prescriptions to adults accounting for 47.2 million (pounds sterling) in expenditure in the United kingdoms ${ }^{12}$ Moreover, there is a inclination of prescribing costly and latest antibiotics these days.

The background that prompted this study was a survey on patient's awareness about the knowledge of antibiotics done from some hospitals and private clinics of Kathmandu that had shown interesting results. ${ }^{11}$ In this study 178 patients were interviewed by a multi graded questionnaire, result showed that $54 \%$ patients had no awareness of antibiotics, $87.1 \%$ had used antibiotics previously, $89.5 \%$ had no knowledge about the side effects of antibiotics. Next another project was done to find out the pattern of antibiotic prescriptions in 20 private clinics and their pharmaco-economics. ${ }^{13}$ was worked out which showed interesting results. In this study 386 prescriptions were audited. Maximum antibiotics were used between 21-40 yr, males were prescribed more antibiotics, only in $20.25 \%$ cases antibiotics were prescribed after proper diagnosis \& sensitivity tests, maximum cost of treatment was 510 Nepali Rupees for treatment of STD in Gynecological clinics.

This project purposely this time concentration was on out patients departments of four major specialties viz medicine, surgery, pediatrics and gynecology in four major government hospitals of Kathmandu valley. along with pharmaco-economic aspects of antibiotics prescriptions were analyzed and discussed.

\section{MATERIALS \& METHOD}

\section{Inclusion \& exclusion criteria :}

The patients in outdoor departments of medicine, surgery, pediatrics and gynecology of four major government hospitals of Kathmandu valley only, and the prescriptions containing antibiotics alone or with other drugs were included in this study. Other specialities, indoor and follow up patients were precluded from this survey.

\section{Study area :}

Prescription audit was done on prescriptions containing antibiotics by contacting patients coming out after consultation with specialist,

SIZE OF DATA : At least fifty encounters receiving antibiotics from each selected hospitals of chosen prescriber. The total size of sample was 522. Prescriptions.

FIELD TEST OF DATA : Field test of the data-collecting tool was done in Om Hospital, Kathmandu.

Coding : The data was coded by following techniques

1. Age distribution: Below 1yr., 1- 10yr, 11-20 yr, 21-30 yr, 31-40y, 41-50y, 51-60yr, >60yr.

2. Sex: Male and female.

3. The total number of drug prescription and the cost of therapy were noted by using SIMS/MIMS/DRUG INDEX.

ANALYSIS OF DATA : Data was tabulated and analyzed using Tally bars, pie diagrams and MS Excel 2000 for windows.

\section{RESULTS}

Age distribution : shown in Table I

Table I : Age Distribution

\begin{tabular}{|c|c|c|c|c|}
\hline AGE GROUP & GYNECOLOGY (n1) & PAED. (n2) & SURGERY (n3) & MEDICINE (n4) \\
\hline$>1 y$ & NA & $\begin{array}{l}7.7 \pm 1.88 \\
10(8 \%)\end{array}$ & NA & NA \\
\hline $1-10 y$ & NA & $\begin{array}{l}7.52 \pm 1.93 \\
110(88 \%) \text { (Max.) }\end{array}$ & $\begin{array}{l}7.46 \pm 1.7 \\
13(10.4 \%)\end{array}$ & NA \\
\hline $11-20 y$ & $\begin{array}{l}16.25 \pm 3.45 \\
8(6.4 \%) \text { (Min.) }\end{array}$ & $\begin{array}{l}14.2 \pm 2.58 \\
5(4 \%) \text { (Min) }\end{array}$ & $\begin{array}{l}16.04 \pm 2.95 \\
22(17.6 \%)\end{array}$ & $\begin{array}{l}15.61 \pm 2.9 \\
18(12.2 \%)\end{array}$ \\
\hline $\begin{array}{l}21-30 y \\
31-40 y\end{array}$ & $\begin{array}{l}25.83 \pm 2.64 \\
83(66.4 \%)(\mathrm{Max})\end{array}$ & $\begin{array}{l}\text { NA } \\
\text { NA }\end{array}$ & $\begin{array}{l}26.21 \pm 2.40 \\
55(44 . \%)(\operatorname{Max})\end{array}$ & $\begin{array}{l}25.93 \pm 2.71 \\
77(52.4 \%)\end{array}$ \\
\hline $41-50 y$ & $\begin{array}{l}46.86 \pm 3.15 \\
15(12 \%)\end{array}$ & NA & $\begin{array}{l}44 \pm 2.16 \\
7(5.6 \%) \text { (Min.) }\end{array}$ & $\begin{array}{l}46.38 \pm 2.27 \\
42(28.5 \%) \\
\end{array}$ \\
\hline $51-60 y$ & & NA & & \\
\hline$>60 y$ & $\begin{array}{l}64.10 \pm 2.44 \\
19(15.2 \%)\end{array}$ & & $\begin{array}{l}64.89 \pm 2.51 \\
28(22.4 \%)\end{array}$ & $\begin{array}{l}64.5 \pm 2.46 \\
10(6.9 \%)\end{array}$ \\
\hline
\end{tabular}

$n 1=125, n 2=125, n 3=125, n 4=147$ No. of encounters $=522$ 
Table II : Sex Distribution

\begin{tabular}{l|cc}
\hline \multicolumn{1}{c|}{ SPECIALITY } & MALE & FEMALE \\
\hline GYNECOLOGY & & 125 \\
\hline MEDICINE & 100 & 47 \\
\hline SURGERY & 85 & 40 \\
\hline PAED. & 67 & 58 \\
\hline
\end{tabular}

Table III : Total numbers of drugs prescribed in the hospitals

\begin{tabular}{cc|c|c|c}
\hline Total No. of & Gyane & Surgery & Medicine & Paed. \\
\hline Prescriptions & 157 & 117 & 109 & 140.
\end{tabular}

Table IV

\begin{tabular}{c}
\hline HEALTH PROBLEMS \\
WHERE ANTIBIOTICS WAS USED, BUT NOT REQUIRED \\
Pain lower abdomen \\
\hline Dysmenorrhoea \\
\hline Aminorrhoea \\
\hline Epigastric pain \\
\hline Pain in chest \\
\hline Abdominal pain \\
Headache, vomiting \\
\hline
\end{tabular}

Table V : Showing percentage of antibiotic prescribed after investigations done in only $24.5 \%$ of cases

\begin{tabular}{c|c}
\hline $\begin{array}{c}\text { ANTIBIOTICS PRESCRIBED } \\
\text { AFTER INVESTIGATIONS }\end{array}$ & PERCENTAGE \\
\hline YES & 24.5 \\
\hline NO & 75.5 \\
\hline OUT OF 24.5\% & 66 \\
\hline GYNECOLOGICAL OPD & 8 \\
\hline MEDICAL OPD & \\
\hline
\end{tabular}

\section{Average number of drugs per prescription}

2.8

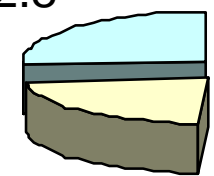

2.34

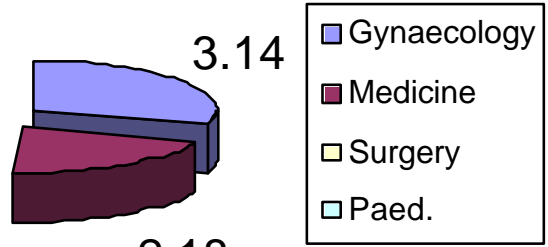

2.18

Fig. 1 : Showing average number of prescriptions in hospitals

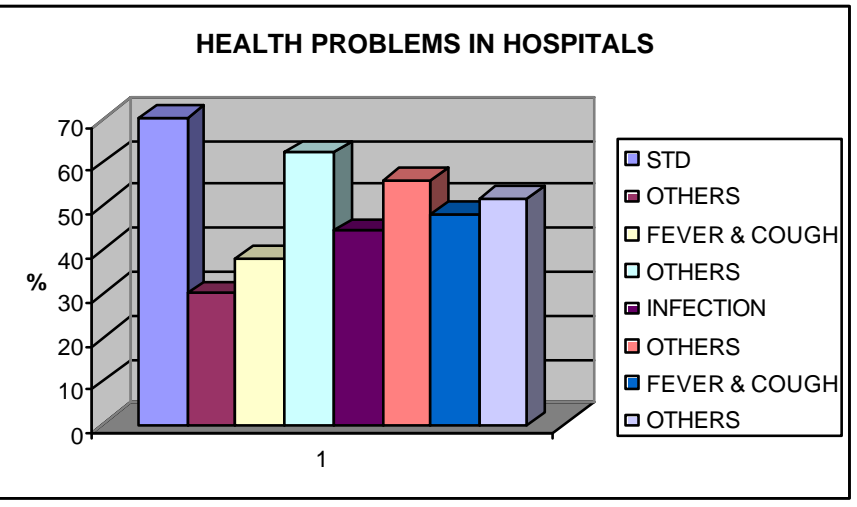

Fig. 2 : Maximum Health Problems
MAX. ANTIBIOTICS USED IN HOSPITALS

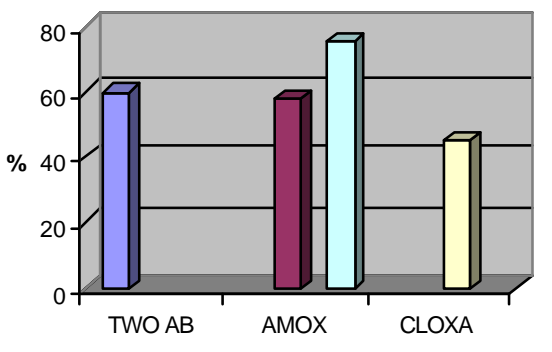

$\square$ STD

$\square$ FEVER \& COUGH $\checkmark$ INFECTION 口 FEVER\&COUGH

Fig. 3 : Showing commonest health problems \& commonest antibiotics used in different specialities in Hospitals

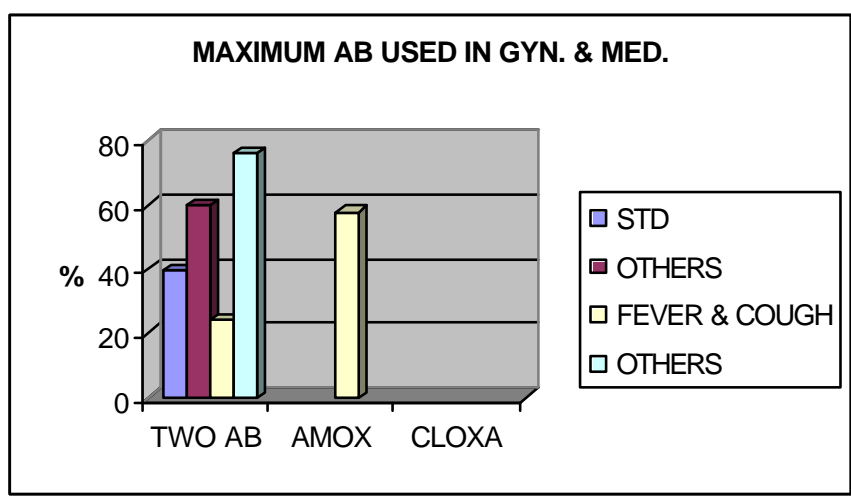

Fig. 4a : Showing antibiotics used in OPD of Hospitals 


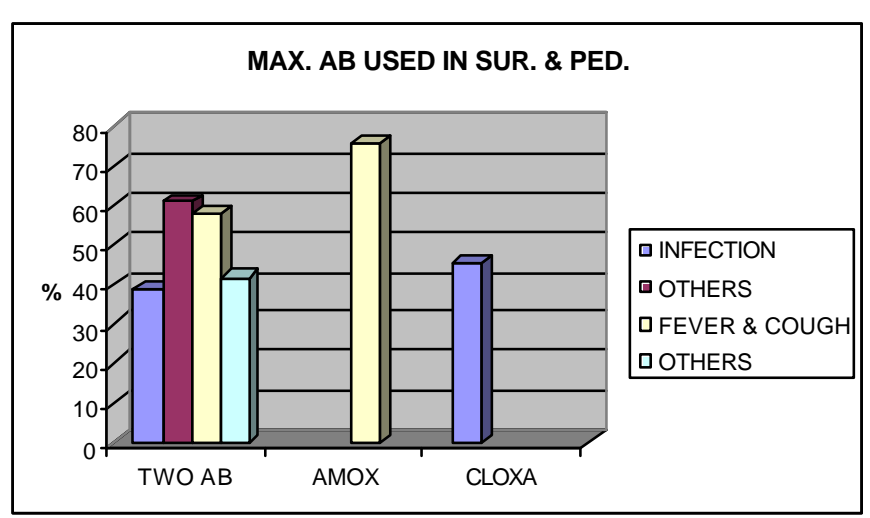

Fig. 4b : Showing antibiotics used in OPD of Hospitals

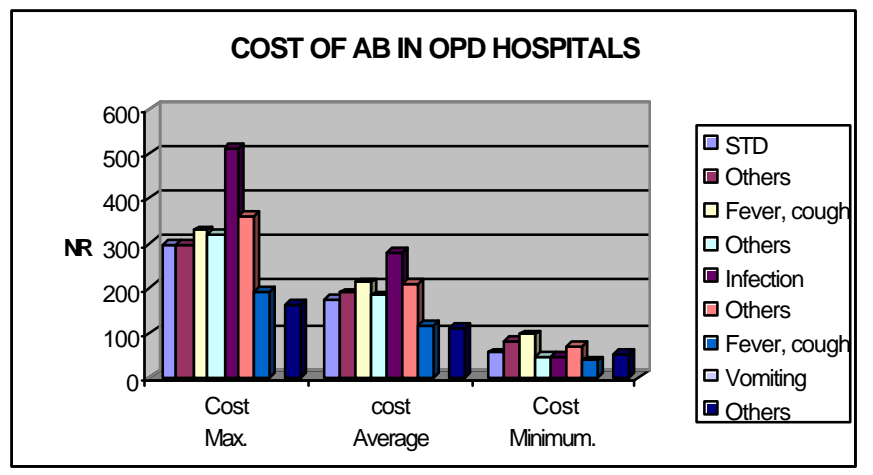

Fig. 5a : Showing pharmaco-economics of antibiotics treatment in all health problems in Hospitals OPD (cost in Nepali Rupees)

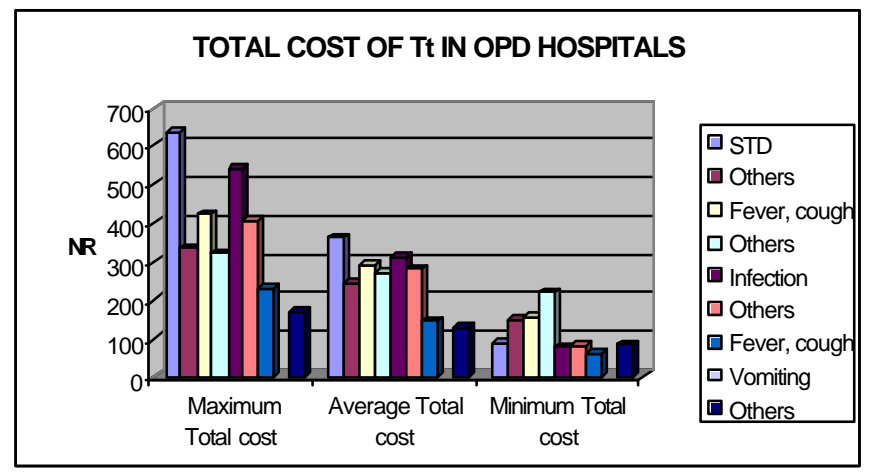

Fig. 5b : Showing pharmaco-economics of antibiotics treatment in all health problems in Hospitals OPD (cost in Nepali Rupees)

Sex distribution : shown in Table II

Males were prescribed more antibiotics then females $(73 \%$ for surgical problems, $62 \%$ for medical problems and 53\% for Pediatric problems

Drug use situation : shown in table III Average number of drugs per prescription (for checking poly pharmacy) has been shown in Pie diagram I.

Health Problems in different specialties : maximum health problems have been shown in bar diagram I.

Use of different antibiotics for different health problems : The use of antibiotics in all types of health problems has been shown in figure I \& II, further the maximum used antibiotics for most frequent health problems has been shown in Bar diagram II. Some of the health problems where antibiotics was used did not require antibiotics treatment has been shown in table IV. antibiotics was prescribed without investigations have been shown in table V.

Graph I \& II : Shows pharmaco-economics of antibiotics treatment in all health problems in Hospitals OPD including total cost of treatment (cost in Nepali Rupees.)

\section{DISCUSSION}

As shown in Table IV is the list of health conditions where antibiotics use was unnecessary and physicians did extra expenditure on antibiotics, which has increased the cost of prescriptions. As shown in this study even taking the average costs of antibiotic's 126, 197.5, 154, 185, 164, 48.5. Nepali Rupees extra expenditure was not required.

Many reports from world over show that antibiotics are used widely and some times indiscriminately which increases the cost of therapy, incidences of ADRs, drug interactions and emergence of resistant bacterial strains. A previous study ${ }^{10}$ documented that nearly three-fourth of indoor patients were prescribed one or more antibiotics. and more than half $(52.7 \%)$ of total expenditure on drugs was on antibiotics.

Table V. Showing percentage of antibiotic prescribed after investigations done in only $24.5 \%$ of cases

\section{PHARMACO-ECONOMIC ASPECTS:}

Pharmaco-economically on average the costliest prescriptions were written by surgeons in cases of infections (average 282 Nepali Rupees) with maximum of 514 Nepali Rupees and minimum of 50 Nepali Rupees. In gynecological problems treatment of STD was costliest amounting to 106 Nepali Rupees with maximum of 295 Nepali Rupees and minimum of 56 Nepali Rupees. Physician's costliest treatment was for fever and cough 214 Nepali Rupees average and maximum of 330 Nepali Rupees and minimum of 98 Nepali Rupees. In Children's diseases prescriptions for upper respiratory infection was costliest 164 Nepali Rupees average, maximum of 292 Nepali Rupees and minimum of 36 Nepali Rupees.

The practice of prescribing antibiotics with out proper culture and sensitivity tests was as high as $75.5 \%$. In over all view the prescriptions of gynecological clinics were costliest, they have been using antibiotics extensively and they prescribed even two antibiotics. Pharmaco-economic implications of this practice are obvious. A question that may arise is that are prescriber aware of the cost of drugs they are prescribing? Some 
studies from U.K. have reported that many prescriber have rather poor knowledge about drug costs. ${ }^{12}$ Considering that antibiotics adds heavily to the total cost of prescription, This is an alarming situation.

\section{RECOMMENDATIONS}

To improve this situation, following may be suggested Prescriber should be more careful in using expensive and multiple antibiotics. Generally oral drugs are cheaper than injections, the older drugs are usually cheaper then the newer ones. ${ }^{14}$ In situations where two or more then two antibiotics are equally effective, cheaper alternative should be the choice, without compromising the patient care. This practice is more pharmaco-economic. There are many common infections that can be treated efficiently with older and cheaper antibiotics. ${ }^{15}$ It may be valuable to categorize antibiotics into different groups and hold some antibiotics in the reserve group for more restricted use. ${ }^{16} \mathrm{~A}$ WHO expert committee (1989) has proposed that antibiotics like quinolones, third \& fourth generation Cephalosporins and vancomycin may be kept as 'reserve' antibiotics for resistant hospital strains infections.

Peer group discussions, availability of sensitivity pattern of local bacterial pathogens can be very helpful in selecting antibiotics, ${ }^{16,17,18}$

? Effective information and dissemination strategies for public at all levels should be implemented.

? A massive consumer awareness programme on the use of antibiotics should be conducted to produce awareness amongst the common people.

? A massive education programme at school level could be ideal. Medical professionals and pharmacists could be invited by school authorities to educate the younger generation not only against antibiotics but also against other health hazards on the lines of AIDS DAY ( $1^{\text {st }}$ of December).

\section{ACKNOWLEDGMENT}

Authors are grateful to Prof. S.K. Bapat, M.D., HOD of Pharmacology KMC \& Prof. V. K. Kulshrestha HOD, Clinical Pharmacology, and Mr. Arun Kumar H.O.D. Department of Clinical Bio-Chemistry, Nepal Medical College, for their generous help. We are thankful to Dr. Navin Thapa, Kathmandu University Medical School and lastly but not the least to Mr. Saffar Mansoor for their guidance.

\section{REFERENCES}

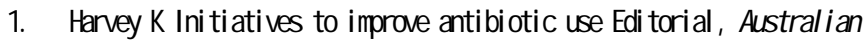
Prescri ber 1999, and vd. 22, 2, 26.
2 Corzd es R Steiner J.F., Sande MA Ati bi otic prescribing for adul ts w th col ds, upper respi ratory tract i infecti ons and bronchi ti s by anbul atory care physi ci ans, J AMA. Septerber 17, 1997 vol. - 278, Nb. 11 901-904.

3 Pel I izzer A M, Cal I anghan CJ. O, Bran ey P, Thonson B \& KrumH Pol ypharnacy in a maj or Austral $i$ an Teachi ng Hospi tal, Aus. J. hosp. Pharnacy 1998, vol 28, Nb. 6, 432-435.

4 Memanus P., Fannond ML., Whi cker S. D. Pri nnose J.G , Nant A \& Fai ral I S.R Anti bi otic use in Austral i an conmoni ty1990-1995 M A 1997, vol. 167, 124- 126.

5 Caper MR Strateges for rati and use of ati indodd ds $\mathrm{Q}$. I If . D s. 1997, (Supd 1): S1546.

6 Pricst P., Yudki n P., NeNulty $C \&$ Mant $D$ Antibacterial prescri bi ing and anti bacteri al resi stance in Eng $\mathrm{i}$ sh general practi ce: cross secti onal study BM, $2001 \mathrm{Vol} .328,1037-$ 1041.

7. Vang-Beringer $A$, Enperi cal Ati microbial prescribing i noact on outcone and cost, Hos. Pharm 1998, vol 33, no. 10, 1208 1213.

8 Jaheri AC \&ohorey AC Ati bi di cs in acte coronery heart di seases Mg 2001, vol. 2, Nb. 2. 103- 104.

9 Kfle KK, Pradran Y.MS, Strestha SB, Prasad RR, Strestha $N \&$ Das P. L Prescribing and di spensi ng practi ces in PHC facilities of Tera d stricts of Nepa J. Inst. Nod 1996, 18, 6166.

10. Joshi M.P., Srivestava K Meda K Study of ati bacterial usage at T.U teaching hospital Tocky s drugs-3, J. I nst. Nad 1991 , 13, 207-213.

11. Pokkere A, Pali khe N, Srestha N J a hari AC\&Rao BS A survey of avareness of anti microbi al agents use in Katmandu valley Mg 2004 (In Press).

12. Rol and F. Grossman, Di sease Managenent of Pul nonary I nf ecti on, GEST 1998, 113: 205S-210S.

13. Pokhere $A$, Pal i khe $N$, Shrestha $N$ J a ahari $A C \&$ Rao BS Pharnaco-economic aspects of anti bi otic prescriptions in sone d i in cs of KathnanduJ MA (Subnitted for pud i cati on).

14. Ryen $M$, Yule $B$, Bond $C$, Tayl or $B$ Scotti sh generd practioner's atti tudes and knowedge in respect of prescri bing costs, B. Ned. J. 1990; 300: 13151318.

15. Sinth $A$ Give a second thangt before using ati bi oti cs led th Acti on 1990: 3, 103-104.

16. Kuri n OM Rati onal use of arti bi otics VHD Dug i f fornation 1990: 4: 47.

17. Lovary BL, Ayliffe GA, Ceddes AM MM I i an日 JDeds. Contro of hospital i iffecti on a practical hand book London: Chapan and Hal I 1981

18. Anonynous Peserve anti bi oti cs VHD Drug i nf or nati on 1989 : 3: 165- 166.

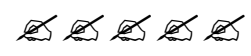

